\title{
Gender Differences in Pelvic and Lower Limb Kinematics during Walking in People with Chronic Low Back Pain
}

\author{
Atefeh Rahimi ${ }^{1 *}$, Amir Masoud Arab ${ }^{1}$ and Mohammad Reza Nourbakhsh ${ }^{2}$ \\ ${ }^{1}$ Department of Physical therapy, University of Social Welfare and Rehabilitation Sciences, Tehran, Iran \\ ${ }^{2}$ Department of Physical therapy, University of North Georgia, Dahlonega, USA
}

*Corresponding author: Atefeh Rahimi, Department of Physical therapy, University of Social Welfare and Rehabilitation Sciences,

Tehran, Iran

\section{ARTICLE INFO}

Received: 慧 July 02, 2020

Published: 幽 July 08, 2020

Citation: Atefeh R, Amir Masoud A, Mohammad Reza N. Gender Differences in Pelvic and Lower Limb Kinematics during Walking in People with Chronic Low Back Pain. Biomed J Sci \& Tech Res 28(4)-2020. BJSTR. MS.ID.004697.

Keywords: Kinematics; Low Back Pain; Lower Limb; Pelvic; Walking
ABSTRACT

Chronic Low back pain (CLBP) is one of the most common musculoskeletal disorders. Previous studies have shown a link between spine and lower limb movement. The link between modified pelvic and lower limb range of motion (ROM) and LBP may vary by gender. Therefore, the purpose of this study was to explore gender differences in pelvic and lower limb kinematics during walking in people with chronic low back pain. Participants included 20 individuals with chronic LBP (10 males). Pelvic and lower limb kinematics was tracked using a seven-camera motion capture system. Oneway ANOVA was conducted to compare the range of motion of pelvis, hip, knee and ankle joints during walking between males and females. Male group showed less pelvic $(\mathrm{P}=0 / 02)$ and ankle $(\mathrm{P}=0 / 03) \mathrm{ROM}$ in sagittal plane compared to female. Additionally, male displayed more ankle ROM in transverse plane $(\mathrm{P}=0 / 01)$ in comparison with female. Males with LBP displayed less motion in the sagittal plane and more motion in the transverse plane in the dominant limb in comparison with females. Therefore, gender specific design of interventions for pelvic and lower limb should be considered to improve CLBP.

Abbreviations: CLBP: Chronic Low Back Pain; ROM: Range of Motion; LBP: Low Back Pain; LPSIS: Left Posterior Superior Iliac Spine; RPSIS: Right Posterior Superior Iliac Spine; RASIS: Right Anterior Superior Iliac Spine; LASIS: Left Anterior Superior Iliac Spine; JCS: Joint Coordinate System; SCS: Segmental Coordinate Systems; HS: Heel Strike

\section{Introduction}

Low back pain (LBP) is one of the most common musculoskeletal disorders affecting more than $80 \%$ of people in their lives [1]. Considering the fact that movement impairments might contribute to the development of musculoskeletal dysfunction and low back pain [2], comparison of movement in people with and without LBP is very important. This determines the mechanical factors that may be related to the development and persistence of LBP. Laird et al [3] demonstrated that people with LBP had a different lumbopelvic movement resulting in reduced lumbar range of motion and to move more slowly [3]. Previous study found a link between spine and lower limb. Accordingly, the spine has been modeled as an inverted pendulum in which a slender column supports the load of the upper body [4-6]. This inverted pendulum requires a shifting base to maintain its stability which is the pelvis bone and lower limbs [4,5]. Therefore, the lumbo-pelvic-hip-knee complex is an important kinematic chain for spine [7]. As a common point of view in previous findings, people with LBP experience modified pelvic, hip, knee and ankle kinematics in clinical tests and during walking [7-11].

The link between modified pelvic and lower limb ROM and LBP, however, may vary by gender. A greater proportion of men than women displayed lumbo pelvic movement impairment are 2-3 times more prevalent in males than females [12]. Regarding muscle strength, joint laxity, tissue extensibility and muscle activation 
patterns, differences exist between males and females [13-17]. These factors impact the biomechanical variables of the lower limb and may cause biomechanical differences in the functional activities such as walking between males and females. In healthy individuals, altered hip and trunk movement have been reported when comparing movement patterns between males and females during lifting style [18,19], reaching task [20], and walking [21]. The effect of gender differences in CLBP population on biomechanics remains unclear. The few studies that have investigated hip and pelvic movement patterns between LBP males and females indicate less active hip medial rotation and earlier lumbo pelvic movement during some clinical tests such as hip rotation in males compared to females [22,23]. Moreover, men with LBP demonstrated significantly increased single limb support time and double limb support time on the dominant limb during walking [24].

Gender differences in spatiotemporal parameters, tissue stiffness and lumbo pelvic pattern may alter lower limb kinematic patterns during walking between men and women. A better understanding of possible gender differences in movement of lower limb during gait could assist in better directing examination and intervention of people with LBP and improve functional outcomes. However, no studies have reported on gender differences in lower limb kinematics in CLBP. Therefore, the purpose of this study was to examine Gender differences in pelvic and lower limb kinematics during walking in people with chronic low back pain.

\section{Material and Method}

\section{Study Participant}

The study participants included 20 patients with CLBP (10 men with $36.72 \pm 8.8$ years of age, height of $174.65 \pm 5.2 \mathrm{~cm}$ and weight of $71.54 \pm 9.9 \mathrm{~kg}$ and 10 women with $38.70 \pm 9.2$ years of age, height of $163.41 \pm 5.3 \mathrm{~cm}$ and weight of $63.90 \pm 6.4 \mathrm{~kg}$ ). Ethical approval was obtained from University of Social Welfare and Rehabilitation sciences ethics committee. The inclusion criteria for the LBP participants consisted of a medical diagnosis of nonspecific LBP, pain and symptoms persisting for longer than 3 months, 1865 years of age, and ambulation without a walking aid. Participants were excluded if they had LBP as a result of traumatic or structural conditions, LBP with neurological symptoms or pain radiation in the lower extremities, spinal tumors or infections, and other neurological and/or musculoskeletal disorder unrelated to LBP.

\section{Procedure}

Three-dimensional motion capture was performed with a seven camera motion tracking system using Qualisys Track Manager
Software (version 2.7) at a frequency of $100 \mathrm{~Hz}$. Retro reflective markers were placed to track the motion of pelvis, hip, knee and ankle. The markers on the pelvis were placed on the left posterior superior iliac spine (LPSIS), right posterior superior iliac spine (RPSIS), right anterior superior iliac spine (RASIS) and left anterior superior iliac spine (LASIS). The markers on lower extremity were placed on greater trochanter, epicondyle, malleolus, calcaneus and first and fifth metatarsal head. Four rigid bodies with four fixed markers were strapped to the thigh and shank. In this study, the kinematics involved the average of five trials of walking across a seven-meter walkway for every participant. The participants were instructed to direct their attention straight ahead and not to target the pathway test. All participants were given adequate rest time between trials in order to minimize the effect of fatigue. Heel strikes were estimated using the minimum in the vertical velocity of the midpoint between the heel and toe markers, and toe off at the maximum in the vertical velocity of the heel marker [25-27]. A stride cycle was defined as the distance between adjacent heel strikes of the same leg. The dominant lower limb was determined by the foot used to kick a ball with maximum strength. The right side was found to be dominant for all participants.

\section{Data Processing}

Three dimensional joint rotations were calculated according to the Joint Coordinate System (JCS). JCS is established based on the two Segmental Coordinate Systems (SCS) [28]. Kinematic data were processed using Visual 3D software (produced by C-motion Company, USA). The specific parameters of interest were range of motion and angles at the time of heel strike (HS) during the gait cycle in sagittal, frontal and transvers planes.

Statistical analyses were completed using SPSS 22 (SPSS, Chicago, IL). Normality was assessed for the dependent variable. Statistical differences in kinematic parameters between groups were determined using Analysis of Variance (ANOVA). An alpha level of 0.05 was used to determine a significant value.

\section{Result}

Our results showed that there were no statistical significant differences between male and female groups in terms of speed and age but height, weight and stride length were significantly difference. Stride length was normalized to the height and this ratio was no statistical significant differences between male and female (Table 1). (Table 2) displays the range of motion (ROM) for pelvis, hip, knee and ankle in the sagittal, frontal and transverse planes during walking. 
Table 1: Demographic and spatiotemporal data.

\begin{tabular}{|c|c|c|c|}
\hline & Female & Male & P-value \\
\hline Age (year) & $38.70 \pm 9.2$ & $36.72 \pm 8.8$ & 0.60 \\
\hline Height (CM) & $163.41 \pm 5.3$ & $174.65 \pm 5.2$ & 0.05 \\
\hline Weight $(\mathrm{Kg})$ & $63.90 \pm 6.4$ & $71.54 \pm 9.9$ & 0.01 \\
\hline BMI $\left(\mathrm{Kg} / \mathrm{M}^{2}\right)$ & $24.54 \pm 2.44$ & $23.31 \pm 2.56$ & 0.27 \\
\hline Speed $\left(\mathrm{M} / \mathrm{Cm}^{2}\right)$ & $0.1 \pm 0.1$ & $0.4 \pm 0.1$ & 0.01 \\
\hline Stride Length $(\mathrm{M})$ & $0.01 \pm 0.0$ & $0.01 \pm 0.01$ & 0.93 \\
\hline
\end{tabular}

Table 2: Mean (SD) of Pelvis, Hip, Knee, Ankle Peak to Peak Range of Motion (ROM) during Gait. *P value <0/05.

\begin{tabular}{|c|c|c|c|c|c|c|}
\hline & \multicolumn{3}{|c|}{ Female } & \multicolumn{3}{|c|}{ Male } \\
\hline & Sagittal & Frontal & Transvers & Sagittal & Frontal & Transvers \\
\hline Pelvic & $\begin{array}{c}* 8.7 \\
-4\end{array}$ & $\begin{array}{c}2.8 \\
-0.8\end{array}$ & $\begin{array}{c}14 \\
-6.3\end{array}$ & $\begin{array}{c}5.2 \\
-1.8\end{array}$ & $\begin{array}{c}2.9 \\
-1.3\end{array}$ & $\begin{array}{c}9.6 \\
-3.5\end{array}$ \\
\hline Hip & $\begin{array}{c}37.4 \\
-3.6\end{array}$ & $\begin{array}{l}13.2 \\
-3.3\end{array}$ & $\begin{array}{c}16.9 \\
-4.8\end{array}$ & $\begin{array}{c}37 \\
-5.1\end{array}$ & $\begin{array}{c}14.4 \\
-3.2\end{array}$ & $\begin{array}{l}16.4 \\
-4.4\end{array}$ \\
\hline Knee & $\begin{array}{l}60.5 \\
-7.6\end{array}$ & $\begin{array}{r}9.6 \\
-3.7\end{array}$ & $\begin{array}{c}15.1 \\
-7\end{array}$ & $\begin{array}{l}59.7 \\
-4.8\end{array}$ & $\begin{array}{c}9.1 \\
-3.6\end{array}$ & $\begin{array}{l}18.8 \\
-6.9\end{array}$ \\
\hline Ankle & $\begin{array}{c}* 27.2 \\
-4.5\end{array}$ & $\begin{array}{l}14.5 \\
-3.5\end{array}$ & $\begin{array}{c}* 10.7 \\
-2.9\end{array}$ & $\begin{array}{c}23.3 \\
-3\end{array}$ & $\begin{array}{l}15.2 \\
-4.4\end{array}$ & $\begin{array}{l}14.9 \\
-2.9\end{array}$ \\
\hline
\end{tabular}

a. Pelvic: Pelvic kinematic of male in all three planes were similar to. However, the only significant difference was the pelvic ROM in the sagittal plane where pelvic moves less in male compared to the female group. They showed 3.5 degrees of less pelvic tilt $(\mathrm{P}=0.02)$

b. Hip: Hip kinematic of male in all three planes was similar to female.

c. Knee: Knee kinematic of male in all three planes was similar to female.

d. Ankle: Ankle kinematic in the male group in the sagittal plane shows less ROM in comparison with the female group and in the transverse plane shows more ROM compared to female group. They showed 4 degrees (14.7\%) of less ankle dorsiflexion $(\mathrm{P}=0.03)$ and 4.2 degrees $(28.18 \%)$ of more ankle adduction $(\mathrm{P}=0.01)$.

\section{Discussion}

The purpose of this study was to compare pelvic, hip, knee and ankle kinematics during gait between male and female with chronic low back pain. The results of the current study indicated that the dominant limb tendency in male was less anterior tilt ROM in pelvic and less dorsiflexion ROM in ankle and more ankle adduction ROM in the transvers plane compared to the dominant limb of female during walking. To our knowledge, this is the first time that pelvis and lower limb kinematics have been evaluated during walking in relation to sex difference in LBP. This study suggests that LBP is associated with differences in gait kinematic variables in males that do not exist in females. Stride length differences did not appear to explain the gender differences in movement during walking. When the stride length measured was normalized to height, there were no statistical differences between male and female. Muscle length may cause the limited ROM in sagittal plane in male compared to female. Healthy men demonstrate decreased lower limb muscle length compared to women [29-32]. If muscle length of hamstring, rectus femoris, iliopsoas and triceps sure a were decreased in male compared to female, it could account for the differences in sagittal plane differences in ROM.

Prior investigators have also suggested a significant gender differences in hip and lumbopelvic pattern in low back pain during hip rotation test. They showed more and earlier pelvic rotation during the clinical test in male $[24,33]$. The limited hip rotation was the main reason, why pelvic rotation in the transvers plane has been increased in male LBP. In the current study pelvic tilt in sagittal plane was significantly less in LBP male than female, but in contrast to previous studies, pelvic rotation and hip flexion and rotation were not statistically significant. The clinical measures of active and passive ROM in those studies are end-range movement in nonfunctional, open-chain movement. However, the differences in endrange passive hip rotation motion are not related to the movement of the hip and pelvic during functional closed-chain activities such as walking in the current study. Additionally, ankle ROM sagittal plane in men LBP is less in comparison with women. It is in consist with the study of Gabriel et al that found, dynamic joint stiffness of the ankle in the sagittal plane in male is higher than female during walking in healthy participants [34]. Muscle activation pattern and properties of triceps sure are some muscle-related factors that can explain gender differences dynamic stiffness of ankle [34]. Regarding the relationship between LBP and plantar flexor length, we believe male LBP are more affected by plantar flexor stiffness. 
Several studies have reported gender differences in lower limb tissue stiffness $[32,35,36]$ that may account for differences in sagittal plane ROM especially in pelvic and ankle during walking Stiffness is defined as the ratio of force or stress applied to the tissue to the change in length or strain of the tissue [37]. Additionally, differences in activation patterns of the hip and knee muscles and decreased recruitment or later activation of the oblique abdominal muscles $[38,39]$ may explain why the ROM of pelvic, knee and ankle differs between men and women in the current study. Men in this study have demonstrated greater ankle and knee motion than women in transvers plane that it may be a compensatory strategy to the decreased available sagittal ROM. Sex differences investigation in foot and ankle has also shown higher medial and lateral arches in females than males $[40,41]$ that can be another explanation for the increased foot transvers motion in male during gait in the current study.

Regardless of the underlying mechanism(s) contributing to the sex differences in pelvic and lower limb motion during walking, the results of the current study suggest that walking and modified ROM may be more problematic for male than female with LBP. Therefore, it could also indicate differences in the focus of treatment for men and women with LBP. If modified pelvic and lower limb ROM during gait is related to gender in LBP, changing in ROM and stiffness can be an effective way to reduce LBP symptoms in male.

\section{Study Limitations}

The first limitation of this study is that walking is not the only complex function of individuals during everyday life, and gender differences in pelvis and lower limb kinematics should preferably be evaluated in other functional postures such as sit-to-stand and stepping. Secondly, it is necessary to examine the joint torque, muscular activity and muscle strength in the lower limb and find its association with the lower limb kinematics in men and women. Thirdly, mechanisms producing different pelvic and lower limb movement during walking between men and women cannot be confirmed by this study. Investigation of kinematics during walking may have provided additional information to improve our understanding of the gender differences in LBP. However, in our opinion, the results of this study are important. Lower limb movement has been becoming a considerable issue in LBP research. This is the first study, to our knowledge, to document differences in pelvic and lower limb motion between men and women in LBP. The findings of this study improve our understanding of factors that could influence the development, persistence and treatment of LBP and may have important clinical implications.

\section{References}

1. GB Andersson (1999) Epidemiological features of chronic low-back pain. The lancet 354(9178): 581-585.

2. S Sahrmann (2002) Diagnosis and treatment of movement impairment syndromes. Elsevier Health Sciences.

3. RA Laird, J Gilbert, P Kent, JL Keating (2014) Comparing lumbo-pelvic kinematics in people with and without back pain: A systematic review and meta-analysis. BMC musculoskeletal disorders 15(1): 1.
4. S Zeinali Davarani, H Hemami, K Barin, A Shirazi Adl, M Parnianpour (2008) Dynamic stability of spine using stability-based optimization and muscle spindle reflex. IEEE Transactions on Neural Systems and Rehabilitation Engineering 16(1): 106-118.

5. N Peter Reeves, KS Narendra, J Cholewicki (2007) Spine stability: The six blind men and the elephant. Clinical Biomechanics 22(3): 266-274.

6. J Meakin, D Hukins, R Aspden (1996) Euler buckling as a model for the curvature and flexion of the human lumbar spine. Proceedings of the Royal Society of London B: Biological Sciences 263(1375): 1383-1387.

7. M Sadeghisani, Manshadi FD, Neda Namnik, Kalantari KK, Rahimi A, et al. (2015) Correlation between Hip Rotation Range-of-Motion Impairment and Low Back Pain. A Literature Review. Ortopedia, traumatologia, rehabilitacja 17(5): 455-462

8. SM Roach, JG San Juan, DN Suprak, M Lyda, AJ Bies, et al. (2015) Passive hip range of motion is reduced in active subjects with chronic low back pain compared to controls. International journal of sports physical therapy 10(1): 13 .

9. DR Burnett, NH Campbell Kyureghyan, RV Topp, PM Quesadab (2015) Biomechanics of lower limbs during walking among candidates for total knee arthroplasty with and without low back pain. BioMed research international 2015: 142562.

10. JW Brantingham, JL Gilbert, J Shaik, G Globe (2006) Sagittal plane blockage of the foot, ankle and hallux and foot alignment-prevalence and association with low back pain. Journal of chiropractic medicine 5(4): 123-127.

11. R Müller, T Ertelt, R Blickhan (2015) Low back pain affects trunk as well as lower limb movements during walking and running. Journal of biomechanics 48(6): 1009-1014

12.SA Scholtes, LR Van Dillen (2007) Gender-related differences in prevalence of lumbopelvic region movement impairments in people with low back pain. journal of orthopaedic \& sports physical therapy 37(12): 744-753.

13. SP Gombatto, DR Collins, SA Sahrmann, JR Engsberg, LR Van Dillen (2006) Gender differences in pattern of hip and lumbopelvic rotation in people with low back pain. Clinical Biomechanics 21(3): 263-271.

14.SA Scholtes, LR Van Dillen (2007) Gender-related differences in prevalence of lumbopelvic region movement impairments in people with low back pain. J Orthop Sports Phys Ther 37(12): 744-753.

15. KJ Cureton, MA Collins, DW Hill, JF Mc Elhannon (1998) Muscle hypertrophy in men and women. Medicine and science in sports and exercise 20(4): 338-344.

16. AJ Bridges, E Smith, J Reid (1992) Joint hypermobility in adults referred to rheumatology clinics. Annals of the Rheumatic Diseases 51(6): 793 796.

17. KK White, SS Lee, A Cutuk, AR Hargens, RA Pedowitz (2003) EMG power spectra of intercollegiate athletes and anterior cruciate ligament injury risk in females. Medicine and science in sports and exercise 35(3): 371 376.

18. WS Marras, KG Davis, M Jorgensen (2003) Gender influences on spine loads during complex lifting. Spine J 3(2): 93-99.

19. WS Marras, SA Ferguson, D Burr, KG Davis, P Gupta (2004) Spine loading in patients with low back pain during asymmetric lifting exertions. The Spine Journal 4(1): 64-75.

20. JS Thomas, DM Corcos, Z Hasan (1998) The influence of gender on spine hip knee and ankle motions during a reaching task. J Mot Behav 30(2): 98-103.

21. LK Smith, JL Lelas, DC Kerrigan (2002) Gender differences in pelvic motions and center of mass displacement during walking: Stereotypes quantified. J Womens Health Gend Based Med 11(5): 453-458.

22. G Mellin (1998) Correlations of hip mobility with degree of back pain and lumbar spinal mobility in chronic low-back pain patients. Spine (Phila Pa 1976) 13(6): 668-670. 
23. AN Sjolie (2004) Low-back pain in adolescents is associated with poor hip mobility and high body mass index. Scand J Med Sci Sports 14(3): 168-175.

24. PS Sung, JT Zipple, P Danial (2017) Gender differences in asymmetrical limb support patterns between subjects with and without recurrent low back pain. Human movement science 52: 36-44.

25. A Hreljac, RN Marshall (2000) Algorithms to determine event timing during normal walking using kinematic data. J Biomech 33(6): 783-786.

26. J Mickelborough, ML van der Linden, J Richards, AR Ennos (2000) Validity and reliability of a kinematic protocol for determining foot contact events. Gait Posture 11(1): 32-37.

27. CM O Connor, SK Thorpe, MJ O Malley, CL Vaughan (2007) Automatic detection of gait events using kinematic data. Gait Posture 25(3): 469474.

28. ES Grood, WJ Suntay (1983) A joint coordinate system for the clinical description of three-dimensional motions: Application to the knee. J Biomech Eng 105(2): 136-144.

29. RS Chow, MK Medri, DC Martin, RN Leekam, AM Agur, et al. (2000) Sonographic studies of human soleus and gastrocnemius muscle architecture: Gender variability. Eur J Appl Physiol 82(3): 236-244.

30. JW Youdas, DA Krause, JH Hollman, WS Harmsen, E Laskowski (2005) The influence of gender and age on hamstring muscle length in healthy adults. J Orthop Sports Phys Ther 35(4): 246-252.

31. M Corkery, Heather Briscoe, Nicole Ciccone, Gina Foglia, Pamela Johnson, et al. (2007) Establishing normal values for lower extremity muscle length in college-age students. Physical Therapy in Sport 8(2): 66-74.

32. KP Granata, SE Wilson, DA Padua (2002) Gender differences in active musculoskeletal stiffness. Part I. Quantification in controlled measurements of knee joint dynamics. Journal of Electromyography and Kinesiology 12(2): 119-126.

ISSN: 2574-1241

DOI: 10.26717/BJSTR.2020.28.004697

Atefeh Rahimi. Biomed J Sci \& Tech Res

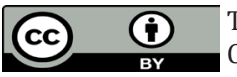

This work is licensed under Creative Commons Attribution 4.0 License

Submission Link: https://biomedres.us/submit-manuscript.php
33. SP Gombatto, DR Collins, SA Sahrmann, JR Engsberg, LR Van Dillen (2006) Gender differences in pattern of hip and lumbopelvic rotation in people with low back pain. Clin Biomech (Bristol, Avon) 21(3): 263-271.

34. RC Gabriel, J Abrantes, K Granata, J Bulas Cruz, P Melo Pinto, et al. (2008) Dynamic joint stiffness of the ankle during walking: Gender-related differences. Physical Therapy in Sport 9(1): 16-24.

35. JT Blackburn, BL Riemann, DA Padua, KM Guskiewicz (2004) Sex comparison of extensibility, passive, and active stiffness of the knee flexors. Clinical Biomechanics 19(1): 36-43.

36. K Granata, D Padua, S Wilson (2002) Gender differences in active musculoskeletal stiffness. Part II. Quantification of leg stiffness during functional hopping tasks. Journal of Electromyography and Kinesiology 12(2): 127-135.

37. M Nordin, VH Frankel (2001) Basic biomechanics of the musculoskeletal system. Lippincott Williams \& Wilkins.

38. BT Zazulak, PL Ponce, SJ Straub, MJ Medvecky, L Avedisian, et al. (2005) Gender comparison of hip muscle activity during single-leg landing. Journal of Orthopaedic \& Sports Physical Therapy 35(5): 292-299.

39.SM Sigward, CM Powers (2006) The influence of gender on knee kinematics, kinetics and muscle activation patterns during side-step cutting. Clinical biomechanics 21(1): 41-48.

40. RE Wunderlich, NL Griffin, AB Wickham (2008) Gender differences in foot function during walking, running and turning: Implications for overuse injuries in female athletes. Clinical Biomechanics 23(5): 705706.

41. M Fukano, T Fukubayashi (2012) Gender-based differences in the functional deformation of the foot longitudinal arch. The Foot 22(1): 6-9.

\begin{tabular}{ll} 
BIOMEDICAL & Assets of Publishing with us \\
RESEARCHES & - Global archiving of articles \\
& - Immediate, unrestricted online access \\
\hline ISSN: $2574-1241$ & - Rigorous Peer Review Process \\
&
\end{tabular}

